\title{
Australia-New Zealand Defence Cooperation: Some Considerations
}

\author{
Jim Rolfe And Arthur Grimes
}

\begin{abstract}
A ustralia and New Zealand have a long history of defence cooperation (currently under the rubric 'Closer Defence Relations' or 'CDR') based on treaty arrangements, on shared values and on similar, although not identical, strategic outlooks. (Rolfe, 1995). Each country has always assumed that the other would come to its assistance in times of military threat. At times the relationship has been very close at others no more than correct. No matter the state of the relationship however, until recently there has been a mutual acceptance of the need for each country to maintain a range of combat capabilities for each of the three services within the respective armed forces. The assumption underlying this seems to have been that broadly-based forces at some level of capability would be able to work with each other to each other's advantage and that between them the two countries would provide the range and quantity of capabilities sufficient to meet any reasonable contingency.

In 2000 each country published reviews giving a framework for decisions on the size and shape of the armed forces for 20 or 30 years (Commonwealth of Australia, 2000; New Zealand Government, 2000). Although Australia explicitly reaffirmed its need to maintain a wide range of combat capabilities, New Zealand's government argued that 'a new approach to defence was one of the key policies of the Government when it was elected' (New Zealand Government, 2000:1). The implication of this was that there could be no guarantees that 'traditional' approaches to size, shape and capabilities would continue.

New Zealand did indeed not follow its traditional approach. Decisions have been taken that degrade New Zealand's combat capacity considerably. Specifically, New Zealand has not taken the option to purchase a third Anzac class frigate (instead deciding to purchase a 'multi-role' naval craft), has deferred any enhancement to, or upgrade of, the capabilities of its anti-submarine aircraft, and has removed the air combat force completely from the order of battle. These moves, especially the removal of the air combat force, are a significant change in the previous strategy of 'wanting a little bit of most things' and a significant shift away Australia's position. Army equipment is to be upgraded, but this will do little more than maintain the Army's capabilities relative to other armies.

Australia's public view of any New Zealand move to remove combat capabilities (declared before the decisions not to add a third frigate to the fleet and to disband the air combat force) is that it "would regret any decision ... not to
\end{abstract}

Jim Rolfe is Associate Professor, Asia-Pacific Center for Security Studies, Hawaii, USA and Arthur Grimes, at the time this article was written, was the Director, Institute of Policy Studies, Victoria University of Wellington, New Zealand. 
maintain at least some capable air and naval combat capabilities' (Commonwealth of Australia 2000:42). A discussion paper prepared before public consultations on defence requirements noted that to optimise Australia's forces for 'operations other than war' (that is, for humanitarian relief, UN observer missions and the like) would be to take Australia 'down the road of New Zealand' (Cheeseman 2000:25). In private, officials and politicians alike are much more scathing of New Zealand's perceived move to irrelevance in regional strategic matters.

These moves raise questions about the long-standing assumption that each country would act to protect the other. Australia because it may see New Zealand as free-riding and not worthy of assistance unless Australia were directly threatened and New Zealand because it would not have the capability. That outcome would be in neither country's interests. It may be though, that despite New Zealand's unilateral approach to force structure issues, both countries can gain. Australia because New Zealand's decisions can be seen as beneficial to both countries rather than harmful to Australia and New Zealand because Australia would not then see New Zealand as free-riding.

In this paper we consider an analytical framework that could usefully inform policy makers when they consider national force capabilities and the degree to which each country can and should cooperate in determining defence structures. We use an explicitly economics approach to our analysis. This takes us away from normative policy statements of 'needs' (which are often 'wants') and gives a clear basis for both making and understanding policy decisions. Initially we examine the domestic determinations of an optimal defence force structure for a small country such as New Zealand. The point of this is to determine to what extent national force structure 'balance' is feasible and either desirable or necessary. We then consider the international considerations facing any small country and how balance applies internationally. Finally, we consider how the concept of balance could apply between Australia and New Zealand. Underlying all this is an assumption that Australia and New Zealand have sufficient interests in common to make cooperation sensible. If that is not the case, of course, then each country should act unilaterally.

Most of the literature applying economic concepts to defence force structure is written chiefly for and about larger countries (for example, Hartley and Sandler, 1995; Sandler and Hartley, 1995). While conceptually the defence structure issues facing a small country are similar to those facing a large country, the emphasis differs. For instance, a large country such as the United States will inevitably have air, navy and army forces, each with various sub-components (such as strike aircraft, bombers and reconnaissance aircraft within the air force). By contrast, it is inevitable that a micro-state such as Tonga will not have all of these force components (and sub-components).

The emphasis in this paper is on issues facing countries that are not in the micro-state category, but which nevertheless are small. New Zealand, with a population of a little fewer than 4 million people is in this category, and many of the issues it faces are common to other small to medium sized countries, including 
Australia. Rolfe (1993 and 1999) gives background on the size and shape of New Zealand's defence forces and on the policy context within which they operate.

\section{Balance}

'Balance' is important, if only as a concept upon which to hang other assertions. Defence force planners in New Zealand have regularly asserted that balance is essential for the armed forces. The concept as it applies to the New Zealand Defence Force (NZDF) is discussed in New Zealand Government (1991 and 1997). One of the 'Key Result Areas' for the NZDF has been 'the enhancement of balanced military capabilities' (New Zealand Defence Force, 2000:39). By this the NZDF has meant that New Zealand should maintain as wide a range as possible of conventional military capabilities. For its part, rather than asserting that balance is 'essential', the Foreign Affairs, Defence and Trade Committee (1999:56) discussed balance as being 'not the same as saying that New Zealand needs a conventional balanced force with three separate services'. This latter view has been adopted by the government. Balance, in the government's view is more to do with having forces relevant to the tasks required of them than it is with having a wider range of forces available for contingencies. In 2000 New Zealand altered its formal position: 'available forces will be concentrated in areas where are they are most needed' (New Zealand Government, 2000:12). Concentration, the antithesis of balance as the term had been used by previous government, has been manifest by the removal of the air combat force.

Balance, however, is not a well-defined concept. New Zealand's armed forces were never 'balanced' in any objective sense of the word. A smallcountry's defence force must inevitably be more specialised (and therefore less 'balanced') than that of the United States, if only because it will not have a nuclear capacity. Policy makers must therefore have a clear idea of what balance means and does not mean, in what circumstances it should be aimed for and how it can best be achieved.

Balance is related to the task or tasks required of the forces under discussion. At the highest level there is a need, in virtually all countries, for a defence force of some kind. The ability to defend a country's own sovereignty in response to particular real or potential threats is generally considered an essential attribute of statehood, and in the worst case may need resort to armed force. A balanced force would be one that could guarantee that security without maintaining more forces than necessary to do so. Regional security (for example, in New Zealand's case, contributions to the security of neighbouring Pacific Island states and of Australia) may come next in priority, followed by broader 'foreign policy' uses of a country's defence force. This may be either in conjunction with an allied or friendly country (such as with each other or the USA or UK in both Australia and New Zealand's case) or with a multilateral body (such as the United Nations). Domestic civil emergency uses may also be important. The size and degree of balance of the armed forces should be determined ultimately by the purposes for 
which they are intended to be used and the weightings given to each of those purposes.

Balance may be achieved nationally through the overall structure of the armed forces, or it may be achieved internationally through coordination across countries (for example between Australia and New Zealand). There may, therefore, be a lack of balance at one level and balance at another. For example, it may be sensible for the defence forces to be unbalanced within a country because there is little likelihood that they will operate without cooperation with other countries, but individual services may be balanced so that they can be sent on operations and act more or less independently of support from other countries in certain circumstances. An important question therefore concerns the level at which balance is needed. These questions regarding balance are central to our analysis here.

\section{Small Country Force Structure: National Considerations}

Of course, any country has both national and international considerations when it considers an optimal force structure. In New Zealand's case the conventional wisdom has been that New Zealand has security interests rather than security needs (New Zealand Government, 1991:28). That being so, force structure will not be optimised to defeat any particular enemy or operate in any particular environment. This is different from the case of a country with an enemy of known or assumed capabilities on its borders or a country that, as a matter of policy, has determined that it will, for example, only defend its own shores and have no expeditionary capability at all.

Domestic considerations relating to an optimal structure for the defence forces depend on a number of factors most importantly including:

- the weighting of various objectives set for defence forces; and

- the aggregate funding available for defence forces.

\section{Influence of Objectives on Structure}

To show how different broad objectives may influence force structure, assume that there are just two objectives for the defence forces. These may be: 'pure defence', relating to sovereignty protection and other warlike operations; and support for foreign policies such as through low-level contributions to the United Nations, or 'presence' rather than war-fighting. These two categories reflect the commonly accepted view that defence forces contribute to multiple, jointlyproduced outputs (see McGuire, 1995; Murdoch, 1995; Sandler and Hartley, 1995).

If New Zealand had just one force element, the Army say, the two outputs would probably be partially rival and partially non-rival: an increase in resources available for the pure defence roles would increase the resources available to support foreign policy aims, but if resources were to be actually employed in 
either role they would not then be available for the other. This introduces the notion of defence forces being an option. More force gives an option for greater contribution to both objectives, even though use for one may crowd out use for the other at any time. ${ }^{1}$ For New Zealand the concept of option is salient because of the accepted wisdom, noted earlier, that the country had defence interests rather than defence needs.

With two or more forces to consider (the Army and the Air Force perhaps), the question becomes more complicated. To illustrate this, consider a force with an Army and an Air Force where both are assumed to contribute equally to the pure defence function, but only the Army contributes to the objective related to the support of the country's foreign policy (the analysis can be extended to more than two force elements, but this merely adds complexity without increasing our understanding of the issues). A balanced force (that is, resources to the Army and the Air Force in the proportion of 50:50) maximises the pure defence objective, but a completely unbalanced force (that is resources to the Army and the Air Force in the proportion of 100:0) maximises the foreign affairs objective as the Air Force does not, by assumption, contribute to that in any case. ${ }^{2}$ It is likely that the government's preferences over both objectives will yield a preferred force structure between the two focused on the Army, but with some Air Force elements being maintained. The ratio of resources to each could be set at 70:30. Such a preferred structure is not optimal from a pure defence viewpoint but it is optimal from a 'national' perspective.

A practical question then arises as to how advice and decisions about defence force structure and funding should be handled. If, say, the defence forces contribute to foreign affairs outputs as well as to pure defence outputs, it makes sense for both foreign affairs and defence officials and other experts to advise on appropriate force structure to ensure that a range of objectives are met. Differing policy-making structures, therefore, could have quite different implications for decisions about force structures. This takes us into the realm of public choice models (Hartley, 1995) with emphasis on the incentives on each agent (including lobbyists) to maximise the outputs (or inputs) under their control (Sandler and Hartley, 1995:57-58).

In New Zealand this kind of analysis has now been made implicitly (although probably not in any rigorously analytical manner). This may be seen in the way the government has expressed force structure preferences based on the ability of the Army to contribute easily to UN operations whereas the Air Force (particularly the air combat force) seems to have a more limited role for these operations and thus has lost its air combat capability.

1 This is quite different from the trade-off between resources for defence and say arts funding: resources used for defence do not give an option for increasing arts outputs (except possibly for an army band!).

2 By our assumption, any force structure with greater than 50 per cent devoted to the foreign policy objective results in a deterioration in both pure defence and foreign policy objectives. Hence the only 'rational' allocation of resources is between 50: 50 and 100:0 to the Army and Air Force respectively. 


\section{Influence of Funding on Structure}

Consider now a situation where there is just one agreed objective for the defence forces, that of pure defence, (the analysis could be extended to multiple objectives as above, but, again, this would complicate the analysis without shedding light). Assume again two potential force elements within the defence force (the Army and the Air Force) and consider the role of funding constraints on the optimal force structure. Two particular aspects may be important:

- the way force elements are linked to specific defence outputs; and

- minimum feasible levels for either or both forces.

\section{Defence outputs}

Consider again the case where defence outputs are a function of the two force elements and examine three alternative situations: ${ }^{3}$

1. We could assume that the total defence output is the sum of expenditures on each of the two forces. In that case both forces should be utilised to the level that additional expenditure on one (within the overall budget) produces a commensurate increase in capability without detracting from the other.

2. We could alternatively assume again that there is expenditure on the both the Army and the Air Force but that the defence output is duplicated by the two; neither does anything that the other does not. In this case only one force element (the most productive one in terms of the desired defence objectives) would be employed.

3. A third case would be where the Army and the Air Force supplement each other and one cannot produce any outputs (again, in terms of the desired defence objectives) without the other. In this case, the overall force must be balanced to be viable at all.

These examples show that there is no necessary reason for a 'balanced' force but rather that the relationship of the force elements to the defence objectives is important.

With multiple defence outputs (such as pure defence and support for foreign policies) therefore, it is possible that each output will have different requirements. For instance pure defence may require balance whereas contributions to UN peacekeeping may be indifferent to the needs of balance (it may not much matter whether a country contributes an army, navy or air force unit to a multilateral

3 Other writers (for example, Warner and Asch, 1995; Sandler and Hartley, 1995) have modelled defence outputs as a function of labour and capital. Since we are primarily interested in force structure, we assume that each force element already embodies an optimised combination (for that force element) of labour and capital and the optimisation calculation is then conducted over the combination of forces. 
force provided it contributes something). In a purely rational world, the government would then require Defence to produce a weighted combination of the two outputs with weightings determined by government preferences. In New Zealand's case though, the history of the usage of the armed forces in the last 50 years and patterns of expenditure on them would seem to indicate that any requirements for 'balance' across the armed forces have had less to do with analysis of the kind discussed and more to do with the kinds of 'bargaining' described in the public choice models discussed above.

\section{Funding and feasibility}

The preceding discussion assumed that there were no minimum levels at which either force had to be maintained in order for it to be operational. In practice this is not normally the case. To take this factor into account, assume that the Army is operable and can contribute to defence outputs at all levels of expenditure, but that the Air Force only contributes once expenditure on it is above a threshold level.

If expenditure on the Air Force is less than the threshold level, the expenditure contributes nothing to defence outputs and is wasted. It would be better to spend nothing on the Air Force and use that expenditure on the Army. But is this optimal? There will be some circumstances where it is and some where it is not. This will depend on whether spending to achieve the pure defence output is higher under the case where there is insufficient expenditure on the Air Force (because the expenditure would be wasted) in which case an unbalanced force structure would be optimal. If on the other hand pure defence is maximised by spending on both the Army and the Air Force, then a balanced structure will be optimal.

The analysis has so far taken aggregate spending as given. However the aggregate level of spending has an important interaction with the effect of the minimum constraint. The more spending there is, the less likelihood there is of the minimum constraint becoming binding.

Consider the policy response to a situation where the optimal size of the Air Force (given a set total defence expenditure level) is less than the required threshold level for effectiveness. There are several policy choices. Firstly, the government could retain the given levels of expenditure and either adopt an otherwise sub-optimal force structure or delete the sub-optimal spending altogether. The choice should depend on the relationship of the Air Force to the Army in the broader production of defence outputs. Secondly, the government could increase defence spending beyond the level it wishes to devote to defence (resulting in a sub-optimal overall allocation of government expenditure) in order to achieve an optimal force structure (viewed purely from a defence force perspective). This indicates a key point: greater defence expenditure not only enables more of the same force elements to be delivered, but also enables more types of force elements to be delivered. The converse also follows.

Sandler and Hartley (1995) argue that declining real defence budgets require a reassessment of force structures both within and across nations. Noting Pugh's 
(1993) analysis that defence costs tend to rise faster than economy-wide costs, they contend (Sandler and Hartley, 1995:116) that 'there are inevitable downward pressures on the size and formation of armed forces' and question the wisdom of 'the long-run trend towards a one-ship navy and a one-aircraft air force'.

This has implications for a small country or, more accurately, for a country with a small overall defence budget. The smaller the defence budget, the more likely it is that the country will adopt an 'unbalanced' force. The United States will maintain all available forces and sub-sets of forces. Tonga has virtually none. New Zealand (and Australia), being small but not microscopic, will optimally be somewhere in between - with the exact number of forces being determined by technological and political preference factors. New Zealand, of course, has determined to maintain its defence budget at relatively low levels and delete capabilities rather than to increase the budget significantly and give itself more options.

If, given this analysis, it makes sense in certain circumstances to reduce the number of force elements (as New Zealand has), why does this frequently not happen? One reason suggested by public choice theory is that bureaucratic incentives of decision-makers are such that they will not recommend such a policy (Sandler and Hartley, 1995:117-119; Rogerson, 1995). Sandler and Hartley (1995:117) claim that instead of rationally prioritising across defence elements in relation to equipment procurement, the reality in some countries may be more bureaucratic:

In reality, such decisions are often made on the principle of Buggins' Turn. Last year, the navy obtained its new aircraft carrier; this year it is the turn of the air force to receive its new fighter aircraft; next year the army can have a new tank!

In New Zealand budgetary considerations are such that expenditure intentions are closely scrutinised. Rarely is there any ability for more than one major equipment procurement at a time. This forces hard decisions and is, in part, the reason for the decisions to reduce the naval combat force and remove the air combat force. ${ }^{4}$

Of course, if there are three force elements (army, navy, air force) but a single specialised force is optimal (no matter what ideological opinion is held), public choice theory implies that there will always be at least two of the three force leaders who advise against specialisation.

Before finishing this section, we foreshadow briefly discussion of the impact that international coordination may have on the structural issues just examined. The analysis in this section has considered a single country in isolation. There is one aspect in which international coordination could relieve a critical constraint for a small country.

\footnotetext{
${ }^{4}$ Of course, that says nothing about any ideological disposition not to have specific combat forces.
} 
Recall the case where the country requires both (or all) forces if any defence output is to be produced. If the country can rely on an ally (either formal or informal) for provision of one force, then the appropriate production function should include the other country's input of that force to the domestic defence effort. This could result in the adoption of an unbalanced rather than a balanced force structure in the smaller country even where an analysis of defence outputs produced by each service would mandate a balanced force in the absence of international cooperation.

\section{Keeping the Options Open}

So far our analysis has been entirely static. However in an uncertain environment, once the time to bring forces to an operational capability is taken into account, the analysis becomes dynamic and further important complexities are introduced. In these circumstances it may become more costly to specialise because the loss of capability arising from the need to bring mothballed forces to readiness must be taken into account.

The impact of this factor on structural choices is, however, complex. While reducing the benefits of specialisation compared with the static case, the need for some specialisation by a small country remains. Quite evidently, the need to retain options is not an argument for a small country to maintain all defence elements maintained by the United States (submarines, nuclear missiles and the like).

The force elements maintained by a small country may in the real world, however, be greater in number than would be the case under a static (and probably) theoretical framework and/or will tend to be more 'generalist' in nature. As an example, if an Air Force is to be maintained, its structure may differ once dynamic factors are taken into account. A static framework with a given environment and given objectives may result in choice of one type of aircraft to carry out a specific function (such as interception of enemy aircraft). However once environmental or other uncertainties related to the range of possible tasks are taken into account, the choice of aircraft may be modified to a model which is capable of carrying out a broader range of functions (both ground attack and interception for example), albeit with a lesser ability to carry out its currently perceived main function, or indeed any of the functions.

A corollary of this analysis is that force elements capable of being used across a broad range of environments and to meet a broad range of objectives will be favoured over force elements which can only be used for narrower tasks. This factor could conceivably result in retention of a specialised defence force (in terms of fewer force elements) if the force elements retained were capable of being used across a broader range of defence outputs (or environments) than could a more 'balanced' force structure. Again, balance is related to the tasks that can be carried out rather than to any specific structure adopted.

It is possible though, that a balanced force would so run down the resources available to the force element appropriate to a specific environment that the 
defence output in that environment would be less than the defence output under a specialised force structure and less that sufficient to be effective. In this case, even though there is environmental uncertainty and we know that in one environment a balanced force will be preferable to a specialised force, the optimal force structure is still a specialised force.

The key result, then, is that environmental (or objective) uncertainty does not automatically lead to the favouring of a balanced force even where a balanced force is preferable under some environments. One must still examine the opportunity costs under alternative environments (or objectives) of maintaining a greater number of force elements.

\section{Small Country Force Structure: International Considerations}

We have taken as given that a government will have a number of (possibly prioritised) objectives for its defence forces. We also take it as given that a sine qua non of any defence force is to protect the country at least from low-level threats to the country's sovereign integrity (such as terrorism or unauthorised incursion into a maritime country's EEZ). Beyond this, a country's optimal defence structure will depend on the national factors discussed above and on a range of international considerations such as the extent and nature of its alliances, and on regional and broader foreign policy objectives to which defence forces might contribute.

This range of potential objectives suggests that decisions about optimal defence structure cannot, in general, be made purely by reference to countryspecific factors. This is so unless the only objective set for the defence force is protection of a country's own sovereignty and even then only if such protection does not involve cooperation with other countries. Once the objective set is extended beyond this, a country's armed forces will necessarily interact with forces of other countries. Hence questions of structures to optimise performance in an international environment must be considered.

For New Zealand, the relationship with Australia is fundamental: 'there is no strategic relationship closer than that with Australia' (New Zealand Government, 2000:6). The relationship is underpinned by both treaty and explicit policy statements, the gist of which are that an attack on either country would be considered to be an attack on the other. The treaty and interest based relationship between Australia and New Zealand does not, however, require either country to conform to the other in terms of either strategic posture or force structure and capabilities. It does suggest though that close coordination should occur (as it does) and that, at the very least, both the capabilities and interests of one country should be taken into account by the other when decisions are being taken. But the optimum outcome is not necessarily clear.

Economic theories of military alliances extend back to the work of Olson and Zeckhauser (1966) who discussed 'deterrence' as a public good and who noted that all lose when defence spending decisions are determined non-cooperatively. But small countries are likely to free-ride in such a situation by 'under-spending' 
on defence forces which contribute to mutual deterrence. Australia has 'perceptions - inaccurate or otherwise - of an imbalance of responsibilities that each country bears within the bilateral relationship' (Rolfe, 1999:71). Indeed analyst Paul Dibb (2000) has described New Zealand as being a 'strategic liability' not a 'cooperative ally'. Even if political coordination across allies prevents such free-riding, choices for a small country differ from those of a large country in terms of whether a country can take other countries' choices as given. In many policy spheres, a small country can take foreign decisions as exogenous and then optimise its own decisions given this environment.

In regional defence where the threat to all members is likely to be similar, however, the approach may (or should) be different. Defence partners (such as New Zealand and Australia) routinely discuss appropriate force structures between themselves, even if they come to no agreement on what is necessary and what is sufficient. A number of justifications may be used for such an approach. Firstly, there is the issue of interoperability (consistency of equipment and processes across forces). As Sandler and Hartley $(1995: 223,339)$ note, if the forces are to work together then a high degree of interoperability is likely to be beneficial. A caveat to this is, of course, where one country (likely to be the smaller) is locked into purchasing inferior or more expensive equipment mandated by the regional partner, perhaps on the basis that the equipment is produced in that country. However, this consideration could be handled via the traditional 'small country' approach: the small country observes or is informed of a larger partner's choices and then takes these as given in making its own decisions. Interoperability per se is not a strong argument for cooperation in determining or influencing structures across the two countries.

A second and better reason could be that a given total defence effort of the two countries could be achieved at lower cost through coordinating their respective structures than if the two countries were to make independent decisions. This reflects an economies of scale argument; defence costs and/or outputs with international coordination may differ from those without coordination.

Take a two country case. One country (Australia, say) is large, and the other (New Zealand) is small. There are two decision-making possibilities: independent and coordinated. In the independent case, New Zealand can observe and take Australia's decisions as given and choose its own defence structure accordingly. Australia must make its choices without necessarily knowing New Zealand's choice. Without coordination, an inefficiency will result. If Australia for some reason cannot count on New Zealand making a sensible decision, or cannot count on it maintaining its 'fair share' of expenditure, Australia would have to maximise its own defence output to achieve its own needs. This would result in a 'balanced' force viewed purely from Australia's perspective, but not necessarily a force balanced for regional security needs. The same is true for New Zealand. If New Zealand takes the resulting Australian force as given, it will find that elements of its own forces will be different from their optimal coordinated level. Depending on the size of the fixed cost and the nature of the production function, it may be optimal (if making decisions independently) for New Zealand also to 
maintain a full range of force elements, at the expense of additional cost and loss of regional balance. This seems to be the position today.

In the coordination case, Australia and New Zealand would cooperate to achieve a common defence objective. If the two countries agree on how much they are individually willing to spend on defence and can coordinate policy, they will maximise their combined defence outputs through fixing the size and capabilities of their respective individual services at appropriate aggregate levels, and ensuring that the structure of forces across the two countries minimises unnecessary fixed costs. With one large and one small country, this is likely to result in the larger country having all capabilities to some level and the smaller country specialising. This is the familiar 'comparative advantage' result discussed in much of the international trade literature. Sandler and Hartley (1995:39) also note that comparative advantage analysis may lead each country within an alliance to specialise in providing sub-sets of security outputs. This results in a balanced force across the two countries. Both countries gain from the adoption of such a force structure compared with the independent decision-making case.

This gain exists even though it results in an 'unbalanced' force (from a single country perspective) in New Zealand which no longer has a particular capability. It also results in an 'unbalanced' force for Australia even though that country has a full range of capabilities. To see this, note that elements of all force elements will be provided by Australia, while New Zealand will provide a larger proportion of one force element (or a few) than its size dictates; thus Australia has a larger ratio of those forces not provided by New Zealand than it would if it were taking a force structure decision in isolation.

Clearly, independent decision-making will be sub-optimal relative to the coordination result (if total expenditures are identical). To see this, note that either country may independently decide on the following options:

1. To adopt a force structure with a full range of force elements.

2. To adopt a limited and specialised force structure.

Option 1 must be inferior to the coordination result since an extra fixed cost is incurred which must lower total defence output for any given level of expenditure compared with the coordination outcome.

Option 2 must be inferior to the coordination result (unless that result is achieved by accident), even though the fixed cost is not incurred, since some elements across the two forces will be below (and others above) the optimal level. Hence the combined defence output is not being maximised.

Importantly therefore, because of the existence of fixed costs, a small country can maximise its contribution to a multi-country defence effort by adopting a small number of well-prepared force elements; the larger the country, the more force elements it will adopt. Essentially, this is a formal derivation of the conjecture by Sandler and Hartley (1995:224) that if NATO members were certain that in the event of an attack their allies would respond, each nation would have an incentive to specialise in its force structures rather than create a totally 
independent capability (each nation with an army, navy, air force). A caveat to this result is that it relies on each country having identical objectives and having certainty about the responses of its allies in circumstances where combined responses are sought. Without identical objectives or certainty, the case for specialisation diminishes - but this is because of a lack of common objectives or certainty; not because of a supposed optimality of each country contributing 'balanced' forces to a common defence force. The case for specialisation also diminishes if a government, for political reasons, is committed to maintaining an independent defence capability (Sandler and Hartley, 1995:226).

At the moment Australia and New Zealand make their decisions more-or-less independently of each other. The result is, therefore, sub-optimal in terms of the countries combined needs, assuming they have both certainty in the other country and more or less identical objectives.

\section{A Specific Case: The New Zealand Air Combat Force}

The Army has been the main defence force element contributed by New Zealand to international operations since World War Two. At times New Zealand has also contributed ships (for example, frigates to the Multinational Interception Force in the Arabian/Persian Gulf) and transport aircraft (especially to carry humanitarian relief). Strike aircraft have been a notable absentee from New Zealand's contribution to international forces over the past three decades despite New Zealand having two A4K Skyhawk squadrons. Strike aircraft were part of New Zealand's commitment to the Commonwealth Far East Strategic Reserve in the 1950s and 1960s. and were used operationally from 1955 to 1960 during the Malayan Emergency and deployed in 1964 during Confrontation with Indonesia.

Despite the lack of operational usage, the air combat force was maintained because of its option value. In 1997 the government (New Zealand Government 1997), set out an investment path for the NZDF consistent with an explicitly stated policy of maintaining a 'balanced' defence force. Balance was most obviously demonstrated by defence expenditure which in 1999 (after abstracting from headquarters expenses) was allocated 37 per cent to the air-force, 33 per cent to the army and 30 per cent to the navy (NZDF, 1999b:19), but was also seen in the maintenance of core combat and support elements for each of the services. Included as a key element of the investment policy was the intention to 'lease 28 F16A/B aircraft. The aircraft are expected to arrive in early 2001 and will replace the 19 A4K Skyhawk aircraft' (NZDF, 1999b:18).

A change of government in late-1999 saw a reassessment of this policy. The new government was less wedded to the idea of New Zealand maintaining a balanced defence force, wishing to focus on optimising New Zealand's defence contribution, especially in international peacekeeping roles. Following establishment of a committee to investigate the F16 lease deal (headed by a former Defence Minister Hon Derek Quigley) which reported favourably on the deal, the government decided, in March 2000, not to proceed with the F16 lease. Prime Minister Helen Clark (2000) stated that while 'the arrangements offered by the 
United States for the F16s were good ones', the F16 acquisition was worthwhile only 'provided that expenditure now on upgrading the air combat force was a priority and that the Defence Force's other priorities were also affordable'. She concluded that this was not the case. In particular (Clark, 2000):

there is no priority setting mechanism in the New Zealand Defence Force which effectively and consistently links individual activities or projects to the government's most pressing national security concerns.

This observation indicates that the new government did not consider the previous matching of resources to objectives to be adequate (that is, the considerations listed earlier in this paper had not been adequately addressed). In background analysis of the F16 deal, Grimes (2000) demonstrated some of the trade-offs incurred in New Zealand maintaining an air strike capacity. That analysis assumed that New Zealand could not realistically scale down the existing capacity; that is, it assumed that an air combat force of 19 aircraft is the minimum required level for the force to exist in a meaningful fashion. Thus the policy choice (consistent with the discussion above) is either to discontinue the force or to keep it at least its current capacity. If the force were discontinued and if aggregate defence funding were maintained constant, the analysis indicates that:

- ready reaction and other army forces could be increased by at least 30 per cent; ${ }^{5}$ or

- at least an additional frigate could be added to the (3-frigate) navy; or

- maritime patrol forces could be more than doubled.

The air combat force has been disbanded and the government has taken decisions to increase total defence expenditure slightly and to substantially bolster the army's equipment but not to materially increase that of either the navy or air force, although patrol craft and a multi-role vessel for the Navy will be acquired.

The issue resulted in extensive discussions with Australian defence planners. Official Australian reaction to New Zealand's decision to remove the air combat force has been largely negative, in part because a key role for New Zealand's strike aircraft included its 'contribution to the defence of Northern Australia' (Wilson-Roberts, 2000; NZDF, 1999b:14) and in part because of a more generalised belief, alluded to earlier, that any diminution of New Zealand's defence capacity is in itself a threat to Australia.

${ }^{5}$ Grimes (2000) also demonstrates that ready reaction and other army force expenditure is much more labour-intensive than is air combat expenditure. The ratio of labour:total expenditure for the ready reaction and related forces is 49 per cent compared with 28 per cent for air combat forces; capital:total expenditure ratios are almost reversed. Given a public policy desire to increase training and employment of lower skilled workers, and a desire to cut imports, a transfer of expenditure from combat aircraft to army forces therefore potentially results in other public policy benefits. 
From our analysis above, the Australian objection possibly rests on faulty analysis. Australia, seven times New Zealand's size, has a sizeable air combat capability. If the two countries could coordinate their defence efforts, it is likely to be optimal for Australia to enlarge its air strike capability by the 20 or so combat aircraft currently retained by New Zealand (reducing its other forces commensurately), leaving New Zealand to enlarge its ready reaction and other army forces by over 30 per cent so as to contribute more strongly to situations such as in East Timor and Bougainville. It appears that, in practice, the New Zealand decision is leading to an increase in the capacity (if not the total numbers) of Australia's air combat force as most of New Zealand's air and ground crews are moving to join the Royal Australian Air Force, thus relieving shortages in that force.

\section{Conclusions}

A small country must decide not only the scale of its armed forces, but also their scope. Inevitably, the smaller a country's defence expenditure, the smaller will be the number of force elements which it can maintain at credible operational levels. Factors which will influence the choice of force structure for a small country include: the nature of defence objectives; the nature of international cooperation amongst national defence forces; the overall level of funding for the armed forces in conjunction with technological factors including the size of fixed costs for each force element; and the degree and nature of environmental uncertainty.

As we move down the continuum of country size, a country must, if it is to establish an optimal force structure, choose to forego defence force elements that would be considered an integral part of the defence force of a larger country. This does not necessarily signify a lack of commitment to defence on the part of such a small country. If anything, it signifies the opposite: a country that is willing to increase its defence contribution by reducing its number of force elements is showing an increased commitment to defence outputs (but not to certain defence careers) given limited resources.

Discontinuing existing force elements, even where this is the optimal path, is subject to potentially severe public choice objections. 'Informed sources' — both domestic and international - may oppose an optimal reprioritisation of defence expenditure, especially where this involves the scrapping of one or more force elements. Governments must then make a decision as to whether to follow a path of optimal resource allocation or a path of least resistance.

Experience suggests that the latter path often predominates. From New Zealand (and other countries') experience, it is likely to take a brave government to decide explicitly to reduce the number of force elements. A more likely scenario (if the 'buggins turn' approach is not adopted) is a long-term run-down in capability of one or more force elements. While this approach retains an option to revitalise that capability in future (more cheaply than if it had been totally discontinued), it is only a second best alternative to discontinuation where the latter is optimal. The latter approach may enable substantial savings in fixed costs 
that could be allocated to enlarge the contributions of other existing force elements. Therefore a choice of defence structure which may on the surface appear the least supportive for defence (that is, discontinuation of a force element) could prove instead to be a significant contributor to bolstering defence outputs.

This analysis has shown that although New Zealand has apparently reduced the capacity of its armed forces, in practice it might well have increased not only its own overall utility (because proper attention will be paid to the Army which will become more effective) but also that of elements of Australia's. If that is the case, then there is considerable scope for the two countries to consider other areas for the armed forces to complement each other (in counter-terrorist capabilities perhaps, or for the defence of northern Australia) and for the total defence effort of the two countries to be enhanced. This would mean a degree of specialisation, more so by New Zealand than Australia. But given that each country is more or less specialised in any case, this would make explicit what is already implicit. A greater barrier is likely to be the question of 'sovereignty' and independence. If the two countries join their armed forces either functionally or at a higher political/constitutional level there will be cries that one or other country has relinquished sovereignty and independence of action. The question of trust and free-riding will also be raised, especially by Australia. These are serious issues, but they are capable of being resolved.

There are advantages to be gained if the two countries could cooperate in their defence planning. There are some caveats of course. Each country would have to be certain of the other's good faith and they would have to be able to agree on a common set (and understanding) of defence objectives. These should not be insurmountable problems. The two countries are closer in outlook and capacity than almost any two others. The two countries already have an economic relationship that is getting ever closer and where that economic relationship has already gone is suitable ground to consider the destination for the defence relationship.

\section{References}

Cheeseman, G. (2000), 'Choosing to Make Choices', Australian Defence Force Journal 143(July/August):25-26.

Clark, H. (2000), 'The F-16 "Fighting Falcon" and the Royal New Zealand Air Force', Media Statement, http://www.airforce.mil.nz/projects/F-16/introduction.html (downloaded 16 January 2000).

Clarke, S. (1999) Strategy, Air Strike and Small Nations, Air Power Studies Centre, RAAF Base, Fairbairn.

Commonwealth of Australia (2000), Defence 2000: Our Future Defence Force, Defence Publishing Service, Canberra.

Dibb, P. (2000), Testimony to the Joint Parliamentary Committee on Foreign Affairs, Defence and Trade, cited in The Age, 28 February. 
Foreign Affairs, Defence and Trade Committee (1999), Inquiry into Defence Beyond 2000, Report, Parliamentary Paper I. 4D, New Zealand House of Representatives.

Grimes, A. (2000) 'F16 Costs: Robustness Testing', A Report for Hon D. Quigley and the New Zealand Treasury, http://www.executive.govt.nz/f16/review15.htm\#robustness.

Hartley, K. (1995), 'Industrial Policies in the Defense Sector', pp. 459-489 (Chapter 16) in K. Hartley and T. Sandler (eds), Handbook of Defense Economics Volume 1, Handbooks in Economics 12, North-Holland Elsevier, Amsterdam.

Hartley, K. and T. Sandler (eds) (1995), Handbook of Defense Economics Volume 1, Handbooks in Economics 12, North-Holland Elsevier, Amsterdam.

McGuire, M. (1995), 'Defense Economics and International Security', pp. 13-43 (Chapter 2) in K. Hartley and T. Sandler (eds), Handbook of Defense Economics Volume 1, Handbooks in Economics 12, North-Holland Elsevier, Amsterdam.

Murdoch, J. (1995), 'Military Alliances: Theory and Empirics', pp. 89-108 (Chapter 5) in K. Hartley and T. Sandler (eds), Handbook of Defense Economics Volume 1, Handbooks in Economics 12, North-Holland Elsevier, Amsterdam.

New Zealand Defence Force (1999a), Departmental Forecast Report: 1 July 1999 - 30 June 2000, House of Representatives Paper G.55 FR (99), Wellington.

New Zealand Defence Force (1999b), Report of the New Zealand Defence Force for the Year Ended 30 June 1999, House of Representatives Paper G.55, Wellington.

New Zealand Defence Force (2000), Report of the New Zealand Defence Force for the Year Ended 30 June 2000, House of Representatives Paper G.55, Wellington.

New Zealand Government (1991), Defence of New Zealand 1991: A Policy Paper, Wellington.

New Zealand Government (1997), The Shape of New Zealand's Defence: A White Paper, Wellington.

New Zealand Government (2000), The Government's Defence Policy Framework, Wellington.

New Zealand Government (2001), A Modern Sustainable Defence Force Matched to New Zealand's Needs, Wellington.

Olson, M. and R. Zeckhauser (1966), 'An Economic Theory of Alliances', Review of Economics and Statistics 48(3):266-279.

Pugh, P. (1993), 'The Procurement Nexus', Defence Economics 4(2):179-194.

Rogerson, W. (1995), 'Incentive Models of the Defense Procurement Process', pp. 309346 (Chapter 12) in K. Hartley and T. Sandler (eds), Handbook of Defense Economics Volume 1, Handbooks in Economics 12, North-Holland Elsevier, Amsterdam.

Rolfe, J. (1993), Defending New Zealand: A Study of Structures, Processes and Relationships, Institute of Policy Studies, Wellington. 
Rolfe, J. (1995), 'Australia and New Zealand: Towards a More Effective Defence Relationship', Working Paper No. 286, Strategic and Defence Studies Centre, Australian National University, Canberra.

Rolfe, J. (1999), The Armed Forces of New Zealand, Allen and Unwin, St Leonards, NSW.

Sandler, T. and K. Hartley (1995), The Economics of Defense, Cambridge Surveys of Economic Literature, Cambridge University Press, Cambridge.

Warner, J. and B. Asch (1995), 'The Economics of Military Manpower', pp. 347-398 (Chapter 13) in K. Hartley and T. Sandler (eds), Handbook of Defense Economics Volume 1, Handbooks in Economics 12, North-Holland Elsevier, Amsterdam.

Wilson-Roberts, G. (ed.) (2000) Australia and New Zealand: The Defence Policy Gulf, CSS Strategic Briefing Paper 4(2), Centre for Strategic Studies, New Zealand.

This work grew out of research conducted for and funded by the New Zealand Treasury. We are grateful to the Treasury for their support. The views expressed herein should be attributed solely to the authors and not to their respective institutions or to the New Zealand Treasury. We thank Ross McLeod and four unnamed referees for their very helpful comments on earlier drafts of this paper. The interpretations and any errors of fact or omission are of course the responsibility of the authors alone. 